OPEN ACCESS

Edited by:

Jun Mei,

Queensland University of Technology, Australia

Reviewed by:

Jigang Zhou,

Canadian Light Source, Canada

Fulai Zhao,

Tianjin University, China

*Correspondence:

Yusuke lde

ide.yusuke@nims.go.jp

Specialty section:

This article was submitted to Electrochemical Energy Conversion and Storage,

a section of the journal Frontiers in Energy Research

Received: 23 November 2020 Accepted: 19 February 2021

Published: 30 March 2021

Citation:

El-Hosainy H, Tahawy R, Esmat M, El-Kemary $M$ and Ide $Y$ (2021) Immobilization of Iron Minerals on a Layered Silicate for Enhancing its Solar Photocatalytic Activity toward

$\mathrm{H}_{2}$ Production.

Front. Energy Res. 9:630535. doi: 10.3389/fenrg.2021.630535

\section{Immobilization of Iron Minerals on a Layered Silicate for Enhancing its Solar Photocatalytic Activity toward $\mathrm{H}_{2}$ Production}

\author{
Hamza El-Hosainy ${ }^{1,2}$, Rafat Tahawy ${ }^{1}$, Mohamed Esmat ${ }^{1}$, Maged El-Kemary ${ }^{2}$ and \\ Yusuke Ide ${ }^{1 *}$ \\ ${ }^{1}$ International Center for Materials Nanoarchitechtonics (WPI-MANA), National Institute for Materials Science, Tsukuba, Japan, \\ ${ }^{2}$ Institute of Nanoscience and Nanotechnology, Kafrelsheikh University, Kafrelsheikh, Egypt
}

The development of efficient and cost-effective solar photocatalysts capable of producing hydrogen from formic acid as a hydrogen storage medium is still a challenging issue. Herein, we report that iron minerals, ferric iron hydroxy sulfates (FHS), immobilized on a natural layered silicate, magadiite, can be used as a photocatalyst to produce hydrogen from formic acid under irradiation with solar simulator. The material exhibits the hydrogen production rate of $470 \mu \mathrm{mol} \mathrm{g}{ }^{-1} \mathrm{~h}^{-1}$, which is considerably higher than that obtained on other iron minerals and comparable to that obtained on precious metal-based photocatalyst ever reported. The present result may open a way to design efficient photocatalyst for hydrogen production from formic acid in an economically and environmentally friendly way.

Keywords: layered silicate, magadiite, iron minerals, photocatalyst, hydrogen storage, formic acid

\section{INTRODUCTION}

Numerous endeavors have been done to develop new strategies that can store and provide hydrogen, an alternative energy source to non-renewable resources including fossil fuels, at acceptable costs (Loges et al., 2010; Grasemann and Laurenczy, 2012; Yadav and Xu, 2012; Li and $\mathrm{Xu}, 2013$; Singh and $\mathrm{Xu}, 2013)$. Due to its availability, non-toxicity, and safe handling in aqueous solutions, formic acid (FA) is one of the most widely investigated hydrogen storage materials and can generate a molecular hydrogen via dehydrogenation reaction $\left(\mathrm{HCOOH} \leftrightarrow \mathrm{H}_{2}\right.$ $+\mathrm{CO}_{2}$ ) (Mori et al., 2013; Bulushev et al., 2016; García-Aguilar et al., 2016; Navlani-García et al., 2018; Podyacheva et al., 2018; Navlani-García et al., 2019). The catalytic hydrogenation of FA based on precious metals such as $\mathrm{Pt}, \mathrm{Pd}$, and $\mathrm{Rh}$ and its alloys have been extensively investigated because they can be operated under relatively mild conditions (Mori et al., 2013; Singh and Xu, 2013; Bulushev et al., 2016; Doustkhah et al., 2018; Podyacheva et al., 2018; Doustkhah et al., 2020). On the other hand, efforts have been recently directed to developing new catalytic systems that can decrease or replace precious metals used (Flaherty et al., 2010; Yi et al., 2013).

Photocatalytic FA hydrogenation has been considered to offer an alternative because the reaction can be done at room temperature using solar energy, available in an unlimited supply. Solids photocatalysts such as $\mathrm{TiO}_{2}$ and $\mathrm{CdS}$ have been used for the reaction after the modification with precious metals such as Ru, Pd, Au, and Pt (Matsumura et al., 1984; Zhang et al., 2010; Li et al., 2011; Cai et al., 2013; Zhang Z et al., 2015). Recently, plasmonic photocatalysts like AuPd nanoalloys 
supported on carbon nitride have been reported to show a relatively high photocatalytic activity for FA hydrogenation (Zhang et al., 2019). While acknowledging these pioneering works, the development of precious-metal-free photocatalytic systems for FA hydrogenation is still challenging.

Here we report that ferric iron hydroxy sulfate (FHS) minerals, hydronium jarosite and volaschioite (Umetsu et al., 1977; Biagioni et al., 2011; Najorka et al., 2016), supported on a natural silicate can be used as a solar photocatalyst for FA hydrogenation. Although iron minerals and iron (oxyhydr) oxides materials, including hematite and akaganeite, have been extensively investigated as photocatalysts toward different reactions due to its low-cost and biocompatibility (Bora et al., 2013; Mishra and Chun, 2015; Ide et al., 2016a; Mani et al., 2018; Ide et al., 2019), to the best of our knowledge, this is the first report to show the solar photocatalytic activity of FHS toward FA hydrogenation. We use a natural layered silicate, magadiite, as the support of FHS because it can be prepared by a simple hydrothermal reaction and possesses a significantly larger density of surface silanol groups (for immobilizing nanoparticles on the surface) than other silicates (Rojo et al., 1988; Ide et al., 2018; Doustkhah and Ide, 2020).

\section{EXPERIMENTAL SECTION}

\section{Materials and Chemicals}

The original (natural) form of magadiite containing sodium cations in the structure, Na-magadiite was purchased from Nippon Chemical Industrial Co., Ltd. Fe $\left(\mathrm{NO}_{3}\right)_{3} \cdot 9 \mathrm{H}_{2} \mathrm{O}$ (99\%) was bought from Nacalai Tesque. $\mathrm{H}_{2} \mathrm{SO}_{4}(97 \%)$ and acetonitrile (99.5\%) were obtained from Wako Pure Chemical Corporation. P25 $\mathrm{TiO}_{2}$ was kindly supplied from Nippon Aerosil Co., Ltd. All chemicals and materials were used without any further purification.

\section{Preparation of H-Magadiite}

Na-magadiite (Na-mag, $10 \mathrm{~g}$ ), was mixed with an aqueous solution of $\mathrm{HCl}(1,000 \mathrm{~mL}, 0.2 \mathrm{M})$ and the dispersion was stirred for 3 days. After separation of the product by centrifugation $(3,500 \mathrm{rpm}, 30 \mathrm{~min})$, the solid was washed with pure water for several times and then dried under vacuum at room temperature. The product was named H-mag.

\section{Preparation of Iron Minerals Deposited on H-mag}

$\mathrm{H}$-mag $(200 \mathrm{mg})$ was mixed with acetonitrile solution $(60 \mathrm{~mL})$ containing $\mathrm{Fe}\left(\mathrm{NO}_{3}\right)_{3} \cdot 9 \mathrm{H}_{2} \mathrm{O}(1800 \mathrm{mg})$. Water $(600 \mu \mathrm{L})$ and $\mathrm{H}_{2} \mathrm{SO}_{4}(1,320 \mu \mathrm{L})$ were added to the mixture and then the mixture was stirred for $1 \mathrm{~h}$. Subsequently, the obtained dispersion was transferred to Teflon-lined stainless-steel autoclave $(100 \mathrm{~mL})$ and solvothermally treated at $100^{\circ} \mathrm{C}$ for $24 \mathrm{~h}$. After the reaction, the solid product was separated by centrifugation $(3,500 \mathrm{rpm}, 30 \mathrm{~min})$ and subsequent decantation, and finally dried at room temperature under
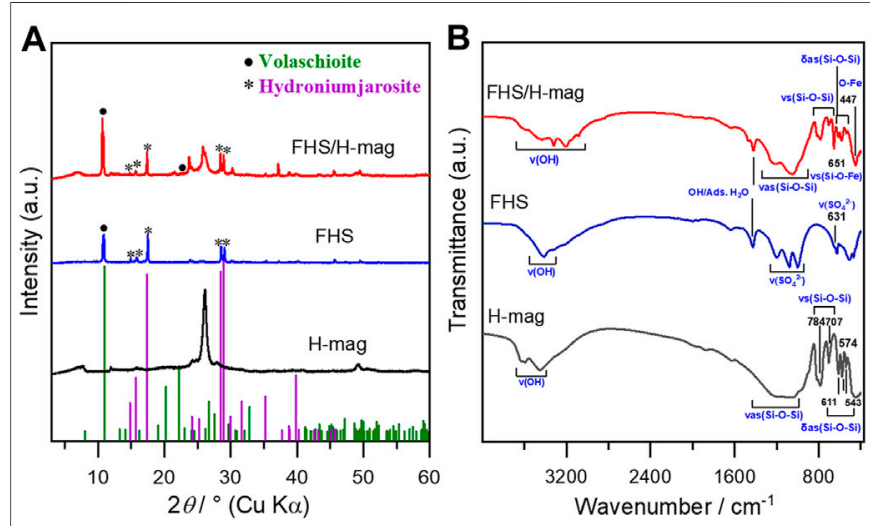

FIGURE 1 | (A) XRD patterns and (B) FT-IR spectra of H-mag, FHS and FHS/H-mag samples.

vacuum overnight. The obtaining product was named FHS/ H-mag. A control sample without H-mag (named FHS) was also prepared by the similar procedure except for adding $\mathrm{H}$-mag. Likewise, $\alpha-\mathrm{Fe}_{2} \mathrm{O}_{3}$ was prepared by the similar procedure except for adding $\mathrm{H}$-mag and $\mathrm{H}_{2} \mathrm{SO}_{4}$.

\section{Characterization}

Powder X-ray diffraction (XRD) patterns were taken utilizing a Rigaku SmartLab diffractometer, with $\mathrm{Cu} \mathrm{Ka}$ radiation at $40 \mathrm{kV}$ and $30 \mathrm{~mA}$ at a scan rate of $1^{\circ} \mathrm{min}^{-1}$. Fourier transform infrared (FTIR) spectra were measured on a Shimadzu FTIR-4200 spectrometer. UV-vis spectra were recorded with a JASCO V-570 spectrometer. $\mathrm{N}_{2}$ adsorption/desorption was carried out at $-196^{\circ} \mathrm{C}$ using a MicrotracBel BELMAX after the samples had been evacuated at $60^{\circ} \mathrm{C}$ for $12 \mathrm{~h}$. Field emission scanning electron microscope (FE-SEM) images were observed with a HITACHI S- 4800 microscope and a Hitachi SU-8230 microscope equipped with energy dispersive X-ray (EDX) spectroscopy analyzer. X-ray photoelectron spectroscopy (XPS) was performed using a PHI Quantera SXM instrument, operated with $\mathrm{Al} \mathrm{Ka}$ radiation at $20 \mathrm{kV}$ and $5 \mathrm{~mA}$. The binding energy shift was calibrated using the $\mathrm{C} 1 \mathrm{~s}$ level at $285.0 \mathrm{eV}$.

\section{Photocatalytic Decomposition/ Dehydrogenation of FA}

Oxidative decomposition and dehydrogenation of FA was performed under $\mathrm{O}_{2}$ and $\mathrm{Ar}$ atmospheres, respectively, in a Pyrex glass tube $(34 \mathrm{~mL})$ as follows: the powder sample $(15 \mathrm{mg})$ was added into an aqueous solution $(5 \mathrm{~mL})$ containing formic acid ( $5 \mathrm{vol} \%$ ) and then bubbled with $\mathrm{O}_{2}$ or Ar for $30 \mathrm{~min}$. Subsequently, the mixture was ultrasonicated for $2 \mathrm{~min}$ and then irradiated via a solar simulator (San-Ei Electric, $\lambda>300 \mathrm{~nm}$, $1,000 \mathrm{Wm}^{-2}$ ) under stirring. The headspace gas in the glass tube was withdrawn with a gas-tight syringe and quantified using a BID gas chromatograph (Shimadzu BID-2010 plus) equipped with a Micropacked ST column. For apparent quantum yield (AQY) calculation, a Pyrex glass tube was irradiated with a 

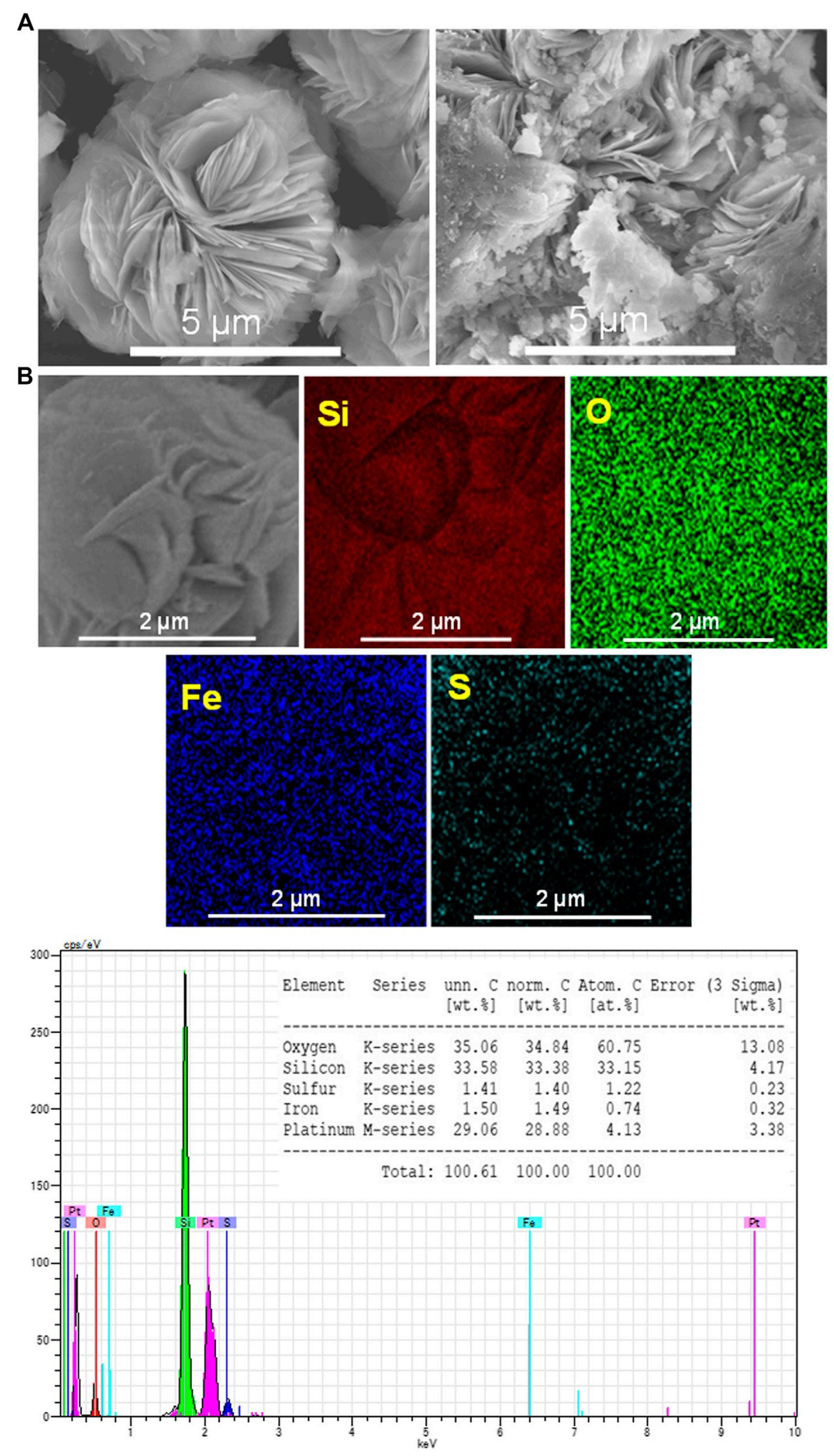

FIGURE 2 | (A) SEM images of H-mag and FHS/H-mag and (B) EDS elemental mappings and EDX spectrum of FHS/H-mag. 


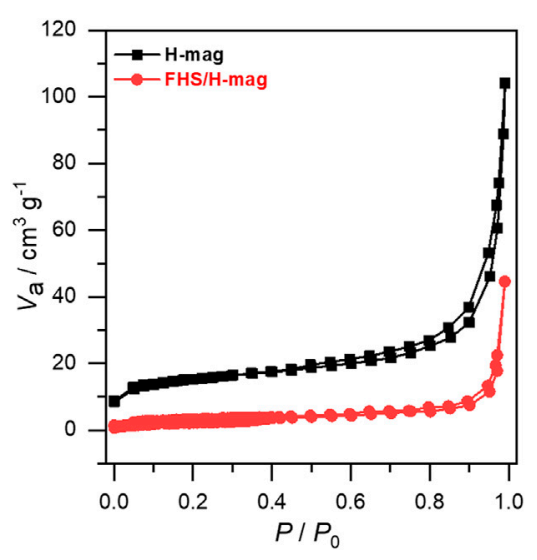

FIGURE 3 | $\mathrm{N}_{2}$ adsorption/desorption isotherms of $\mathrm{H}$-mag and FHS/ H-mag.

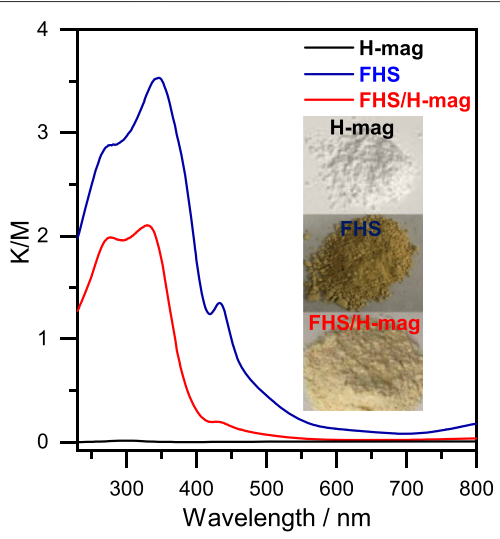

FIGURE 4 | UV-Vis spectra of H-mag, FHS and FHS/H-mag. Inset shows the photographs of each powder.

monochromated light using an Ushio $500 \mathrm{~W}$ Xe lamp equipped with a Bunkoukeiki SM-25 monochromator. The number of incident photons was determined using a Bunkoukeiki S1337-1010BQ silicon photodiode. AQY (\%) was defined as [number of $\mathrm{H}_{2}$ evolved] $\times 2 /$ [number of incident photons] $\times 100$.

\section{RESULTS AND DISCUSSION}

FHS minerals, hydronium jarosite and volaschioite with chemical formulas of $\left(\mathrm{H}_{3} \mathrm{O}\right) \mathrm{Fe}_{3}\left(\mathrm{SO}_{4}\right)_{2}(\mathrm{OH})_{6}$ and $\mathrm{Fe}_{4}\left(\mathrm{SO}_{4}\right)$ $\mathrm{O}_{2}(\mathrm{OH})_{6}\left(\mathrm{H}_{2} \mathrm{O}\right)_{2}$, respectively, are metastable phases relative to hematite and converted to hematite at elevated temperature (Umetsu et al., 1977; Biagioni et al., 2011; Najorka et al., 2016). Thus, we had investigated the effect of temperature on the formation of FHS on $\mathrm{H}$-mag in the reactions of $\mathrm{H}$-mag with $\mathrm{Fe}\left(\mathrm{NO}_{3}\right)_{3} \cdot 9 \mathrm{H}_{2} \mathrm{O}$ solution containing $\mathrm{H}_{2} \mathrm{SO}_{4}$. At room temperature and $50^{\circ} \mathrm{C}$, no particles were deposited on $\mathrm{H}$-mag. In contrast, iron species, which later was confirmed to be FHS, was deposited on $\mathrm{H}$-mag (FHS/H-mag) when the reaction was conducted at $100^{\circ} \mathrm{C}$.

Figure 1A shows the XRD patterns of FHS/H-mag and $\mathrm{H}$-mag. FHS/H-mag gave diffractions peaks due to hydronium jarosite and volaschioite, in addition to those of $\mathrm{H}$-mag. The position and intensity of the peak due to the basal spacing for FHS/H-mag observed at around $2 \theta$ of $7.5^{\circ}$ was not significantly different from that of $\mathrm{H}$-mag. These results suggest the formation of FHS phases mainly outside H-mag particles.

FTIR also shows the presence of FHS in the FHS/H-mag sample (Figure 1B). FHS/H-mag had an absorption band at $447 \mathrm{~cm}^{-1}$ assigned to the vibrations in $\mathrm{FeO}_{6}$ of FHS (Ristic et al., 2005; Wei and Nan, 2011), in addition to those at 543, 574 , and $611 \mathrm{~cm}^{-1}$ assigned to the $\mathrm{Si}-\mathrm{O}-\mathrm{Si}$ bending vibration, those at 707 and $784 \mathrm{~cm}^{-1}$ attributed to the Si-O-Si stretching vibration, and those from 1,000 to $1,260 \mathrm{~cm}^{-1}$ assigned to the Si-O-Si asymmetric stretching vibration (Kooli et al., 2001). Note that the characteristic absorption band due to the sulfate $\left(\mathrm{SO}_{4}{ }^{2-}\right)$ moiety of FHS, which should be observed in the range of $900-1,300 \mathrm{~cm}^{-1}$ (Ristić et al., 2005), are overlapped by the absorption bands due to the silicate framework. Importantly, FHS/H-mag, moreover, had an absorption band at $651 \mathrm{~cm}^{-1}$ assignable to the $\mathrm{Si}-\mathrm{O}-\mathrm{Fe}$ vibration (Szostak et al., 1987). All these results demonstrate that the FHS phases are immobilized on the surface of H-mag particles. XRD and FTIR data also confirmed that a control sample, sole FHS, is composed of hydronium jarosite and volaschioite.

To investigate the location of the immobilized FHS, SEM-EDX analysis was performed. As shown in Figure 2A, H-mag is composed of rosette-like aggregates of large plate-like crystals with a size of ca. $2 \mu \mathrm{m}$. On the other hand, FHS/H-mag is also composed of similar rosette-like aggregates but their surface is partially rough and disordered due to the presence of smaller particles attached. From the EDX elemental mapping of FHS/ H-mag (Figure 2B), Fe and S elements are entirely distributed on each rosette-like aggregate. Moreover, the EDX spectrum of FHS/ $\mathrm{H}$-mag indicates that the $\mathrm{Fe}, \mathrm{S}$, and $\mathrm{Si}$ contents in $\mathrm{FHS} / \mathrm{H}$-mag is $1.5,1.4$, and $33.5 \mathrm{wt} \%$, respectively. Note that Fe and $\mathrm{S}$ were also detected on particles other than rosette-like aggregates while the amount of the former particles were considerably smaller than that of the latter particles.

Nitrogen adsorption-desorption isotherms measurements further confirmed the morphology of FHS/H-mag. As shown in Figure 3, FHS/H-mag showed a significantly decreased external surface area compared to $\mathrm{H}$-mag. This result means that small FHS segments covers rosette-like aggregates or fill the angularities of the aggregates. All the results described above indicate that FHS are immobilized in a highly dispersed state on the particle outer surface of $\mathrm{H}$-mag for $\mathrm{FHS} / \mathrm{H}$-mag.

The optical properties of $\mathrm{FHS} / \mathrm{H}-\mathrm{mag}$ were investigated (Figure 4). In contrast to $\mathrm{H}$-mag that is white, $\mathrm{FHS} / \mathrm{H}$-mag is light yellow. UV-Vis absorption spectra revealed that FHS/ $\mathrm{H}$-mag had an absorption onset around $550 \mathrm{~nm}$ like sole FHS. We thus expected that FHS/H-mag could be used as photocatalysts working under solar light irradiation. 

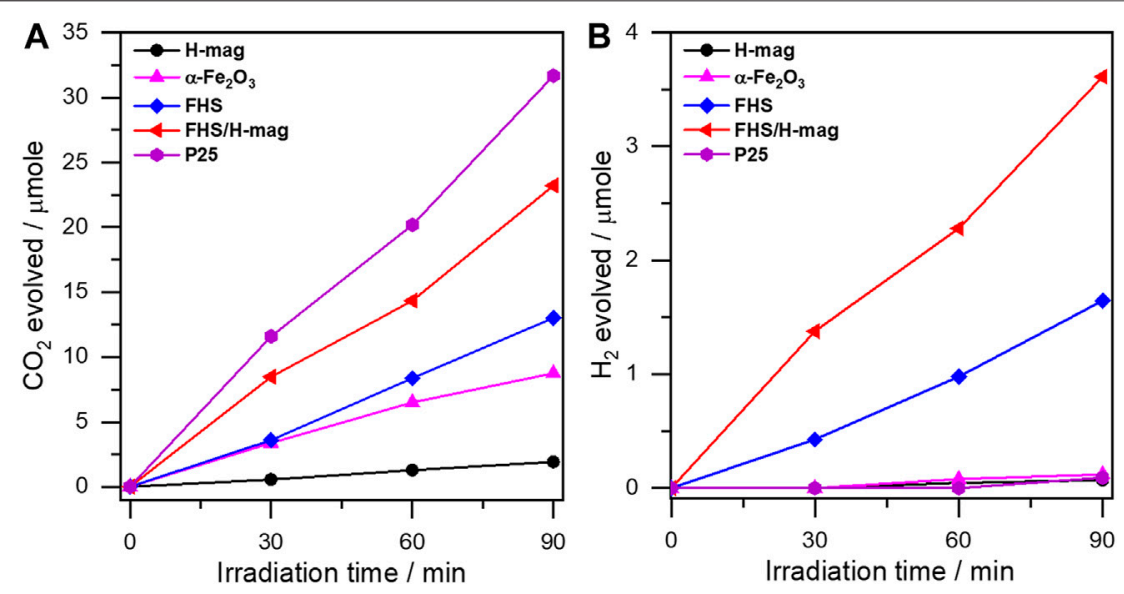

FIGURE 5 | (A) $\mathrm{CO}_{2}$ evolution and (B) $\mathrm{H}_{2}$ evolution profiles on different materials from an aerated aqueous solution containing $\mathrm{FA}$ under solar simulator irradiation.
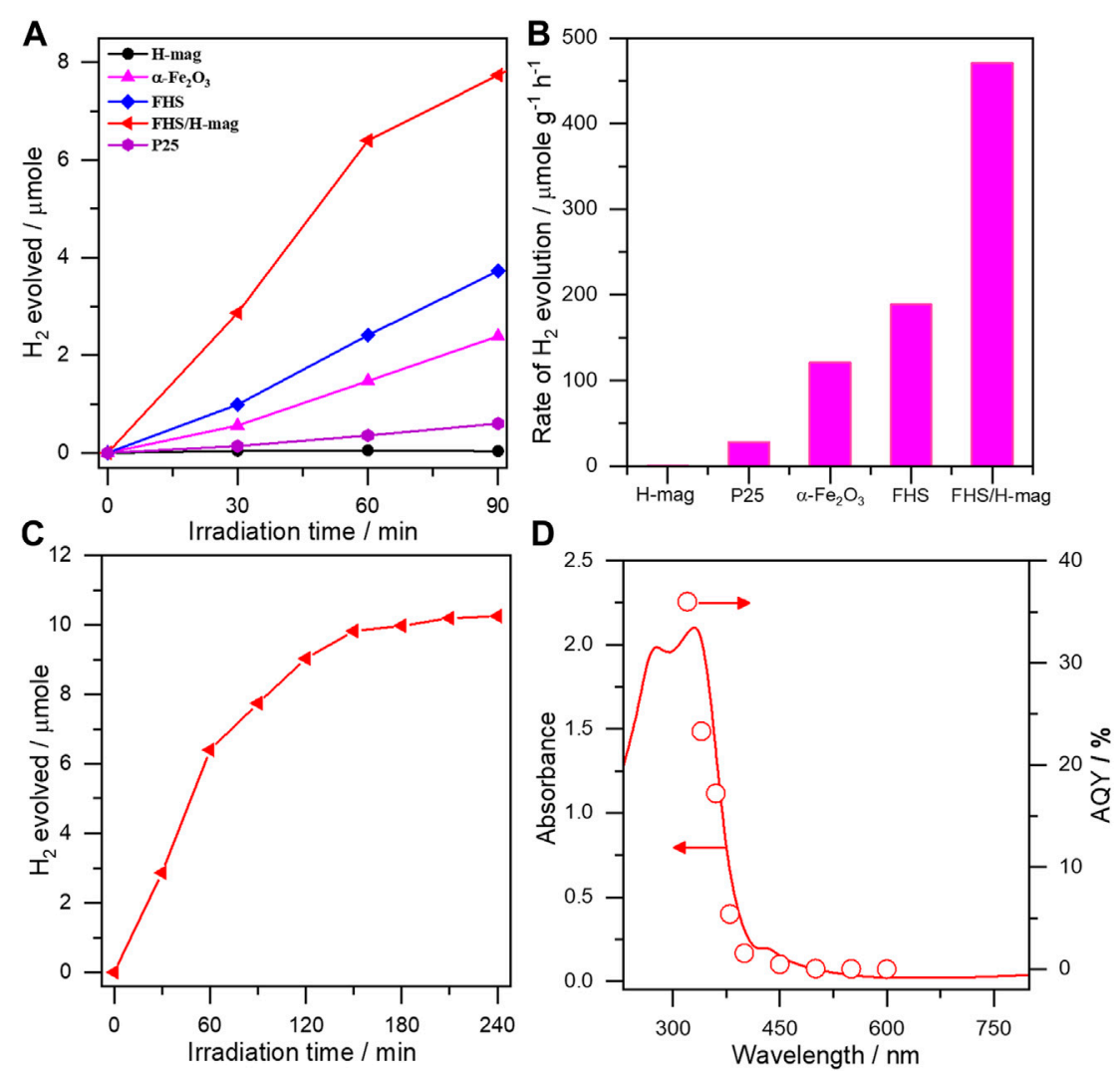

FIGURE 6 | (A) $\mathrm{H}_{2}$ evolution profiles (B) $\mathrm{H}_{2}$ evolution rates on different materials from a deaerated aqueous solution containing FA under solar simulator irradiation (C) Durability test for $\mathrm{FHS} / \mathrm{H}$-mag and (D) Action spectrum in photocatalytic dehydrogenation of $\mathrm{FA}$ on $\mathrm{FHS} / \mathrm{H}$-mag.

The photocatalytic activity of FHS/H-mag was firstly evaluated via the oxidation of $\mathrm{FA}$ to evolve $\mathrm{CO}_{2}$, a representative reaction to check the performance of the synthesized photocatalysts (Kominami et al., 2010; Ide and
Komaguchi, 2015; Ide et al., 2016b; Saito et al., 2016). As shown in Figure $5 \mathbf{A}$, the amount of evolved $\mathrm{CO}_{2}$ required for $\mathrm{FA}$ oxidation on FHS/H-mag increased linearly with the irradiation time, showing the photocatalysis of FHS/H-mag 


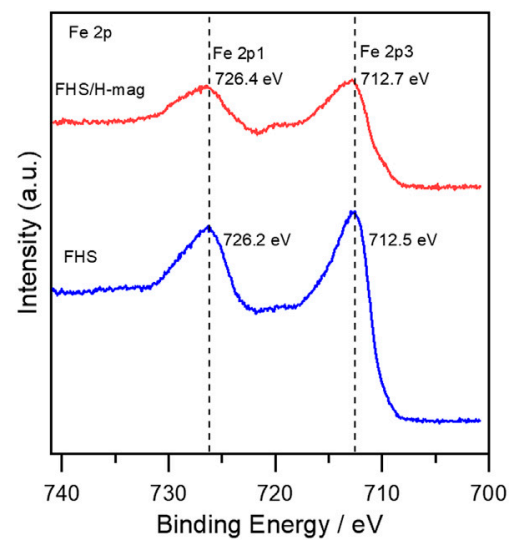

FIGURE 7 |Fe 2p-region XPS spectra of FHS and FHS/H-mag samples.

toward this reaction. This result, considering that $\mathrm{H}$-mag was inactive for this reaction, indicates the photocatalytic activity of the FHS component of FHS/H-mag. Importantly, with the same sample amount $(15 \mathrm{mg})$, FHS/H-mag, having only $1.5 \mathrm{wt} \%$ of the immobilized $\mathrm{Fe}$, showed a high $\mathrm{CO}_{2}$ evolution rate comparable to that of P25, a benchmark $\mathrm{TiO}_{2}$ photocatalyst, and significantly higher than that of a typical iron mineral, $a-\mathrm{Fe}_{2} \mathrm{O}_{3}$ (hematite) and sole FHS. These results demonstrate the high photocatalytic activity of the immobilized FHS for FHS/H-mag. Furthermore, to our surprise, FHS/H-mag produced $\mathrm{H}_{2}$ even in the presence of $\mathrm{O}_{2}$ as shown in Figure 5B. Generally, the photocatalytic decomposition of organic compounds, including $\mathrm{FA}$, into $\mathrm{CO}_{2}$ proceeds efficiently with $\mathrm{O}_{2}$ probably because $\mathrm{O}_{2}$ is reduced with photoexcited electrons to produce a relatively stable superoxide radical anion and then electron-hole recombination is retarded (Nosaka et al., 1997; Ohtani et al., 2008). FHS/H-mag could reduce FA in competition with $\mathrm{O}_{2}$; thus, we also expected its high photocatalytic activity toward FA dehydrogenation (reduction).

As expected, FHS/H-mag showed a high $\mathrm{H}_{2}$ production rate that is considerably higher than that obtained on P25 and a- $\mathrm{Fe}_{2} \mathrm{O}_{3}$ with the same sample amount (Figures 6A,B). We could not detect $\mathrm{CO}$ at all but $\mathrm{CO}_{2}$, confirming the photocatalytic FA dehydrogenation ability of FHS/H-mag. To compare the photocatalytic activity of FHS/H-mag objectively, we calculated the hydrogen evolution rate as $470 \mu \mathrm{mol} \mathrm{g}^{-1} \mathrm{~h}^{-1}$. This value was comparable to that reported for $\mathrm{Rh}-\mathrm{N}-\mathrm{TiO}_{2}$ $\left(750 \mu \mathrm{mol} \mathrm{g}{ }^{-1} \mathrm{~h}^{-1}\right), \mathrm{Cu}-\mathrm{TiO}_{2}\left(830 \mu \mathrm{mol} \mathrm{g}{ }^{-1} \mathrm{~h}^{-1}\right)$ and $\mathrm{Ru}-\mathrm{CdS}$ supported on a zeolite $\left(540 \mu \mathrm{mol} \mathrm{g}^{-1} \mathrm{~h}^{-1}\right)$ (Zhang et al., 2010; Halasi et al., 2012; Lanese et al., 2013). The photocatalytic activity of FHS/H-mag was significantly higher than that of sole FHS. FHS/H-mag showed the durability against the photocatalytic reaction by approximately $3 \mathrm{~h}$-irradiation (Figure 6C).

We investigated the reason for the high activity of FHS/ $\mathrm{H}$-mag. It has been reported that $\mathrm{Fe}$ (III)-salen complex integrated with $\mathrm{CdS}$ photocatalytically yields $\mathrm{H}_{2}$ from FA. The proposed photocatalytic mechanism involves 1) the

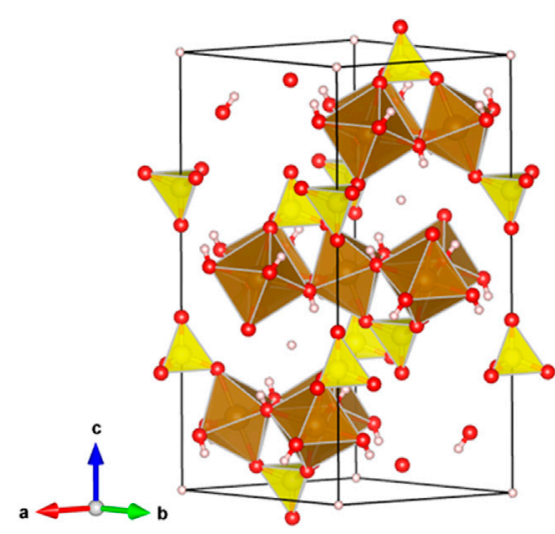

FIGURE 8 | Crystal structure of hydronium jarosite showing an example of $\mathrm{Fe}$ (III) cites in FHS that can interact with the surface of H-mag. Color coding: pink $=\mathrm{H}$, red $=\mathrm{O}$, yellow $=\mathrm{S}$, brown $=$ Fe.

adsorption of FA on CdS to produce formate $\left.\left(\mathrm{HCOO}^{-}\right), 2\right)$ the band gap excitation of CdS generates an electron/hole pair and the photogenerated hole oxidizes formate to produce $\mathrm{CO}_{2}{ }^{-}$and $\mathrm{H}^{+}, 3$ ) the $\mathrm{Fe}(\mathrm{III})$ complex rapidly accepts the photogenerated electron from the excited CdS to produce $\mathrm{Fe}(\mathrm{II})$ species, 4) transfer of another electron from $\mathrm{CO}_{2}{ }^{-}$to $\mathrm{Fe}(\mathrm{II})$ species produces $\mathrm{Fe}(\mathrm{I})$ species which effectively reduce $\mathrm{H}^{+}$to yield $\mathrm{H}_{2}$ (Irfan et al., 2020). In the present case, the immobilized FHS can act as a semiconductor photocatalyst enabling to both oxidize formate to produce $\mathrm{H}^{+}$and reduce $\mathrm{H}^{+}$to yield $\mathrm{H}_{2}$. This scenario is suggested by the action spectrum of FHS/H-mag in FA dehydrogenation (Figure 6D), in which AQY on FHS/H-mag for $\mathrm{H}_{2}$ evolution well-correlated with the photo-adsorption of FHS/H-mag.

We, moreover, investigated the effect of the hybridization between FHS and H-mag on the high activity of FHS/H-mag. The Fe 2p XPS spectra for FHS and FHS/H-mag revealed that the oxidation state of Fe ions is mainly trivalent (Zhang X et al., 2015) and the Fe $2 \mathrm{p}$ peak for $\mathrm{FHS} / \mathrm{H}$-mag appeared at a higher binding energy region than that for FHS (Figure 7). This result suggests that $\mathrm{Fe}(\mathrm{III})$ sites in the FHS component (Figure 8) of FHS/H-mag becomes more cationic (Eguchi et al., 2017) and thus the adsorption of FA (formation of formate) is enhanced, in addition to that the FHS component is immobilized on the surface of H-mag particles.

\section{CONCLUSION}

We have reported the synthesis of iron minerals, ferric iron hydroxy sulfates (hydronium jarosite and volaschioite) supported on a layered silicate, magadiite, via a simple hydrothermal reaction of the silicate with a solution containing iron nitrite $\mathrm{Fe}\left(\mathrm{NO}_{3}\right)_{3} \cdot 9 \mathrm{H}_{2} \mathrm{O}$ and $\mathrm{H}_{2} \mathrm{SO}_{4}$. We demonstrated that the iron minerals were immobilized in a highly dispersed state and showed an impressive solar 
photocatalytic activity toward FA dehydrogenation comparable to that obtained on precious metal-based photocatalysts ever reported. The material design presented here is flexible to design supported photocatalysts based on different iron minerals. This paper thus may open a way to create highly efficient preciousmetal free solar photocatalysts for $\mathrm{H}_{2}$ production from $\mathrm{H}_{2}$ storage materials.

\section{DATA AVAILABILITY STATEMENT}

The raw data supporting the conclusions of this article will be made available by the authors, without undue reservation.

\section{REFERENCES}

Biagioni, C., Bonaccorsi, E., and Orlandi, P. (2011). Volaschioite, $\mathrm{Fe}_{4}^{3+}\left(\mathrm{SO}_{4}\right)$ $\mathrm{O}_{2}(\mathrm{OH})_{6} 2 \mathrm{H}_{2} \mathrm{O}$, a new mineral species from fornovolasco, apuan alps, tuscany, Italy. Can. Mineral. 49, 605-614. doi:10.3749/canmin.49.2.605

Bora, D. K., Braun, A., and Constable, E. C. (2013). "In rust we trust". Hematite-the prospective inorganic backbone for artificial photosynthesis. Energy Environ. Sci. 6, 407-425. doi:10.1039/c2ee23668k

Bulushev, D. A., Zacharska, M., Shlyakhova, E. V., Chuvilin, A. L., Guo, Y., Beloshapkin, S., et al. (2016). Single isolated $\mathrm{Pd}^{2+}$ cations supported on $\mathrm{N}$-doped carbon as active sites for hydrogen production from formic acid decomposition. ACS Catal. 6, 681-691. doi:10.1021/acscatal.5b02381

Cai, Y.-Y., Li, X.-H., Zhang, Y.-N., Wei, X., Wang, K.-X., and Chen, J.-S. (2013). Highly efficient dehydrogenation of formic acid over a palladium-nanoparticlebased mott-Schottky photocatalyst. Angew. Chem. Int. Ed. 52, 11822-11825. doi:10.1002/anie.201304652

Doustkhah, E., Hasani, M., Ide, Y., and Assadi, M. H. N. (2020). Pd nanoalloys for $\mathrm{H}_{2}$ generation from formic acid. ACS Appl. Nano Mater. 3, 22-43. doi:10.1021/ acsanm.9b02004

Doustkhah, E., and Ide, Y. (2020). Microporous layered silicates: old but new microporous materials. New J. Chem. 44, 9957-9968. doi:10.1039/c9nj06222j

Doustkhah, E., Rostamnia, S., Zeynizadeh, B., Kim, J., Yamauchi, Y., and Ide, Y. (2018). Efficient $\mathrm{H}_{2}$ generation using thiourea-based periodic mesoporous organosilica with Pd nanoparticles. Chem. Lett. 47, 1243-1245. doi:10.1246/ cl. 180537

Eguchi, M., Momotake, M., Inoue, F., Oshima, T., Maeda, K., and Higuchi, M. (2017). Inert layered silicate improves the electrochemical responses of a metal complex polymer. ACS Appl. Mater. Inter. 9 (40), 35498-35503. doi:10.1021/ acsami.7b13311

Flaherty, D. W., Berglund, S. P., and Mullins, C. B. (2010). Selective decomposition of formic acid on molybdenum carbide: a new reaction pathway. J. Catal. 269, 33-43. doi:10.1016/j.jcat.2009.10.012

García-Aguilar, J., Navlani-García, M., Berenguer-Murcia, Á., Mori, K., Kuwahara, Y., Yamashita, H., et al. (2016). Evolution of the PVP-Pd surface interaction in nanoparticles through the case study of formic acid decomposition. Langmuir 32, 12110-12118. doi:10.1021/acs.langmuir.6b03149

Grasemann, M., and Laurenczy, G. (2012). Formic acid as a hydrogen source-recent developments and future trends. Energ. Environ. Sci. 5, 8171-8181. doi:10.1039/c2ee21928j

Halasi, G., Schubert, G., and Solymosi, F. (2012). Photolysis of HCOOH over Rh deposited on pure and $\mathrm{N}$-modified $\mathrm{TiO}_{2}$. Catal. Lett. 142, 218-223. doi:10.1007/ s10562-011-0740-x

Ide, Y., Iwata, M., Yagenji, Y., Tsunoji, N., Sohmiya, M., Komaguchi, K., et al. (2016a). Fe oxide nanoparticles/Ti-modified mesoporous silica as a photocatalyst for efficient and selective cyclohexane conversion with $\mathrm{O}_{2}$ and solar light. J. Mater. Chem. A. 4, 15829-15835. doi:10.1039/c6ta04222h

Ide, Y., Nagao, K., Saito, K., Komaguchi, K., Fuji, R., Kogure, A., et al. (2016b). h-BN nanosheets as simple and effective additives to largely enhance the activity of $\mathrm{Au} / \mathrm{TiO}_{2}$ plasmonic photocatalysts. Phys. Chem. Chem. Phys. 18, 79-83. doi:10.1039/c5cp05958e

\section{AUTHOR CONTRIBUTIONS}

HE: Methodology, Investigation, Writing-original draft. RT: Investigation. ME: Investigation. ME: Supervision, Investigation. YI: Conceptualization, Writing—review andamp; editing—original draft, Supervision.

\section{ACKNOWLEDGMENTS}

We would like to gratefully acknowledge the financial support by joint supervision scholarship from Cultural Affairs and Missions Sector, Egyptian Ministry of Higher Education.

Ide, Y., and Komaguchi, K. (2015). A photocatalytically inactive microporous titanate nanofiber as an excellent and versatile additive to enhance the $\mathrm{TiO}_{2}$ photocatalytic activity. J. Mater. Chem. A. 3, 2541-2546. doi:10.1039/ c4ta06027j

Ide, Y., Tominaka, S., Kono, H., Ram, R., Machida, A., and Tsunoji, N. (2018). Zeolitic intralayer microchannels of magadiite, a natural layered silicate, to boost green organic synthesis. Chem. Sci. 9, 8637-8643. doi:10.1039/ c8sc03712d

Ide, Y., Tominaka, S., Yoneno, Y., Komaguchi, K., Takei, T., Nishida, H., et al. (2019). Condensed ferric dimers for green photocatalytic synthesis of nylon precursors. Chem. Sci. 10, 6604-6611. doi:10.1039/c9sc01253b

Irfan, R. M., Wang, T., Jiang, D., Yue, Q., Zhang, L., Cao, H., et al. (2020). Homogeneous molecular iron catalysts for direct photocatalytic conversion of formic acid to syngas $\left(\mathrm{CO}+\mathrm{H}_{2}\right)$. Angew. Chem. 132, 14928-14934. doi:10.1002/ ange. 202002757

Kominami, H., Tanaka, A., and Hashimoto, K. (2010). Mineralization of organic acids in aqueous suspensions of gold nanoparticles supported on cerium (IV) oxide powder under visible light irradiation. Chem. Commun. 46, 1287-1289. doi:10.1039/b919598j

Kooli, F., Kiyozumi, Y., and Mizukami, F. (2001). Conversion of protonated magadiite to a crystalline microporous silica phase via a new layered silicate. ChemPhysChem 2, 549-551. doi:10.1002/1439-7641(20010917)2:8/ $9<549:$ :aid-cphc549>3.0.co;2-i

Lanese, V., Spasiano, D., Marotta, R., Di Somma, I., Lisi, L., Cimino, S., et al. (2013). Hydrogen production by photoreforming of formic acid in aqueous copper/TiO2 suspensions under UV-simulated solar radiation at room temperature. Int. J. Hydrogen Energ. 38, 9644-9654. doi:10.1016/j.ijhydene. 2013.05.101

Li, S.-L., and Xu, Q. (2013). Metal-organic frameworks as platforms for clean energy. Energ. Environ. Sci. 6, 1656-1683. doi:10.1039/c3ee40507a

Li, Y., He, F., Peng, S., Gao, D., Lu, G., and Li, S. (2011). Effects of electrolyte $\mathrm{NaCl}$ on photocatalytic hydrogen evolution in the presence of electron donors over Pt/TiO 2 . J. Mol. Catal. A: Chem. 341, 71-76. doi:10.1016/j.molcata.2011.03.026

Loges, B., Boddien, A., Gärtner, F., Junge, H., and Beller, M. (2010). Catalytic generation of hydrogen from formic acid and its derivatives: useful hydrogen storage materials. Top. Catal. 53, 902-914. doi:10.1007/s11244-010-9522-8

Mani, D., Tsunoji, N., Yumauchi, Y., Arivanandhan, M., Jayavel, R., and Ide, Y. (2018). Templated synthesis of atomically thin platy hematite nanoparticles within a layered silicate exhibiting efficient photocatalytic activity. J. Mater. Chem. A. 6, 5166-5171. doi:10.1039/c7ta10427h

Matsumura, M., Hiramoto, M., Iehara, T., and Tsubomura, H. (1984). Photocatalytic and photoelectrochemical reactions of aqueous solutions of formic acid, formaldehyde, and methanol on platinized cadmium sulfide powder and at a cadmium sulfide electrode. J. Phys. Chem. 88, 248-250. doi:10.1021/j150646a017

Mishra, M., and Chun, D.-M. (2015). $\alpha-\mathrm{Fe}_{2} \mathrm{O}_{3}$ as a photocatalytic material: a review. Appl. Catal. A: Gen. 498, 126-141. doi:10.1016/j.apcata.2015.03.023

Mori, K., Dojo, M., and Yamashita, H. (2013). Pd and Pd-Ag nanoparticles within a macroreticular basic resin: an efficient catalyst for hydrogen production from formic acid decomposition. ACS Catal. 3, 1114-1119. doi:10.1021/cs400148n 
Najorka, J., Lewis, J. M. T., Spratt, J., and Sephton, M. A. (2016). Single-crystal $\mathrm{X}$-ray diffraction study of synthetic sodium-hydronium jarosite. Phys. Chem. Minerals 43, 377-386. doi:10.1007/s00269-016-0802-0

Navlani-García, M., Mori, K., Kuwahara, Y., and Yamashita, H. (2018). Recent strategies targeting efficient hydrogen production from chemical hydrogen storage materials over carbon-supported catalysts. NPG Asia Mater. 10, 277-292. doi:10.1038/s41427-018-0025-6

Navlani-García, M., Mori, K., Salinas-Torres, D., Kuwahara, Y., and Yamashita, H. (2019). New approaches toward the hydrogen production from formic acid dehydrogenation over pd-based heterogeneous catalysts. Front. Mater. 6, 1-18. doi:10.3389/fmats.2019.00044

Nosaka, Y., Yamashita, Y., and Fukuyama, H. (1997). Application of chemiluminescent probe to monitoring superoxide radicals and hydrogen peroxide in $\mathrm{TiO}_{2}$ Photocatalysis. J. Phys. Chem. B 101, 5822-5827. doi:10. 1021/jp970400h

Ohtani, B., Nohara, Y., and Abe, R. (2008). Role of molecular oxygen in photocatalytic oxidative decomposition of acetic acid by metal oxide particulate suspensions and thin film electrodes. Electrochemistry 76, 147-149. doi:10.5796/electrochemistry.76.147

Podyacheva, O. Y., Bulushev, D. A., Suboch, A. N., Svintsitskiy, D. A., Lisitsyn, A. S., Modin, E., et al. (2018). Highly stable single-atom catalyst with ionic Pd active sites supported on $\mathrm{N}$-doped carbon nanotubes for formic acid decomposition. ChemSusChem 11, 3724-3727. doi:10.1002/cssc.201801679

Ristić, M., Musić, S., and Orehovec, Z. (2005). Thermal decomposition of synthetic ammonium jarosite. J. Mol. Struct. 744-747, 295-300. doi:10.1016/j.molstruc. 2004.10.051

Rojo, J. M., Ruiz-Hitzky, E., and Sanz, J. (1988). Proton-sodium exchange in magadiite. Spectroscopic study (NMR, IR) of the evolution of interlayer $\mathrm{OH}$ groups. Inorg. Chem. 27, 2785-2790. doi:10.1021/ic00289a009

Saito, K., Kozeni, M., Sohmiya, M., Komaguchi, K., Ogawa, M., Sugahara, Y., et al. (2016). Unprecedentedly enhanced solar photocatalytic activity of a layered titanate simply integrated with $\mathrm{TiO}_{2}$ nanoparticles. Phys. Chem. Chem. Phys. 18, 30920-30925. doi:10.1039/c6cp05635k

Singh, A. K., and Xu, Q. (2013). Synergistic catalysis over bimetallic alloy nanoparticles. ChemCatChem 5, 652-676. doi:10.1002/cctc.201200591

Szostak, R., Nair, V., and Thomas, T. L. (1987). Incorporation and Stability of Iron in Molecular-sieve Structures. Ferrisilicate analogues of zeolite ZSM-5. J. Chem. Soc., Faraday Trans. 83, 487-494. doi:10.1039/F19878300487
Umetsu, V., Tozawa, K., and Sasaki, K.-i. (1977). The hydrolysis of ferric sulphate solutions at elevated temperatures. Can. Metallurgical Q. 16, 111-117. doi:10. 1179/cmq.1977.16.1.111

Wei, C., and Nan, Z. (2011). Effects of experimental conditions on onedimensional single-crystal nanostructure of $\beta$-FeOOH. Mater. Chem. Phys. 127, 220-226. doi:10.1016/j.matchemphys.2011.01.062

Yadav, M., and Xu, Q. (2012). Liquid-phase chemical hydrogen storage materials. Energ. Environ. Sci. 5, 9698-9725. doi:10.1039/c2ee22937d

Yi, N., Saltsburg, H., and Flytzani-Stephanopoulos, M. (2013). Hydrogen production by dehydrogenation of formic acid on atomically dispersed gold on ceria. ChemSusChem 6, 816-819. doi:10.1002/cssc.201200957

Zhang, S., Li, M., Zhao, J., Wang, H., Zhu, X., Han, J., et al. (2019). Plasmonic AuPd-based Mott-Schottky photocatalyst for synergistically enhanced hydrogen evolution from formic acid and aldehyde. Appl. Catal. B: Environ. 252, 24-32. doi:10.1016/j.apcatb.2019.04.013

Zhang, X., Ge, J., Lei, B., Xue, Y., and Du, Y. (2015). High quality $\beta-F e O O H$ nanostructures constructed by a biomolecule-assisted hydrothermal approach and their pH-responsive drug delivery behaviors. CrystEngComm 17, 4064-4069. doi: $10.1039 / \mathrm{c} 5 \mathrm{ce} 00559 \mathrm{k}$

Zhang, Y. J., Zhang, L., and Li, S. (2010). Synthesis of Al-substituted mesoporous silica coupled with CdS nanoparticles for photocatalytic generation of hydrogen. Int. J. Hydrogen Energ. 35, 438-444. doi:10.1016/j.ijhydene.2009.11.004

Zhang, Z., Cao, S.-W., Liao, Y., and Xue, C. (2015). Selective photocatalytic decomposition of formic acid over AuPd nanoparticle-decorated $\mathrm{TiO}_{2}$ nanofibers toward high-yield hydrogen production. Appl. Catal. B: Environ. 162, 204-209. doi:10.1016/j.apcatb.2014.06.055

Conflict of Interest: The authors declare that the research was conducted in the absence of any commercial or financial relationships that could be construed as a potential conflict of interest.

Copyright (c) 2021 El-Hosainy, Tahawy, Esmat, El-Kemary and Ide. This is an openaccess article distributed under the terms of the Creative Commons Attribution License (CC BY). The use, distribution or reproduction in other forums is permitted, provided the original author(s) and the copyright owner(s) are credited and that the original publication in this journal is cited, in accordance with accepted academic practice. No use, distribution or reproduction is permitted which does not comply with these terms. 